\title{
PATTERNS OF DIFFICULTY IN VOCABULARY
}

\author{
ROBERT LADO \\ University of Michigan
}

\section{Words.}

1. 1 Undue emphasis on words as words to the neglect of pronunciation and grammatical structure is not in keeping with modern linguistic thinking. Sapir says bluntly in talking about linguistic study, "The linguistic student should never make the mistake of identifying a language with its dictionary." " On the other hand, one cannot deny or ignore the existence of the word as a tangible unit of language. Sapir again, with characteristic insight, puts it thus:

No more convincing test could be desired than this, that the naĩve Indian, quite unaccustomed to the concept of the written word, has nevertheless no serious difficulty in dictating a text to a linguistic student word by word; he tends, of course, to run his words together as in actual speech, but if he is called to a halt and is made to understand what is desired, he can readily isolate the words as such, repeating them as units. He regularly refuses, on the other hand, to isolate the radical or grammatical element, on the ground that it "makes no sense." 2

1.2 The word has been defined for scientific linguistic study by Bloomfield:

A free form which consists entirely of two or more lesser free forms, as, for instance, poor John or John ran away or yes, sir, is a phrase. A free fiorm which is not a phrase, is a word. A word, then, is a free form which does not consist entirely of (two or more) lesser free forms; in brief, a word is a minimum free form.

\footnotetext{
${ }^{1}$ Edward Sapir, Language, (New York, 1921), p. 234.

${ }^{2}$ Ibid, pp. 34-35.

${ }^{3}$ Leonard Bloomfield, Language, (New York, 1933), pp. 177-178. For a more complete discussion of the word see also pp. 178-183 and 207-
} 


\section{LANGUAGE LEARNING}

1.3 A clear insight into the way words are used by the speakers of a language is given by Fries. He says,

For us, a word is a combination of sounds acting as a stimulus to bring into attention the experience to which it has become attached by use....

More than that, while the experience that is stimulated by the sound combination is a whole with a variety of contacts, usually only one aspect of this experience is dominant in attention-a particular aspect determined by the whole context of the linguistic situation. When one uses head in such a context as "a head of cabbage," it is the shape which is the dominant aspect of the experience that has made a connection with the material unit, a cabbage. When one uses head in such a context as "the head of a department," it is the head as the chief or dominating part of the body. When it is used in "the head of the river," another aspect of the relation of head to the body is important in attention. From a practical point of view, the various separate dictionary meanings of a word are the particular aspects of the experience stimulated by a word that have been dominant in the attention of users of the word as these aspects may be inferred from the context of a large number of quotations in which the word appears. For the native user of a language, the symbol, with the wide range of experience it stimulates, is so much a part of the very texture of his thought that he exercises great freedom in turning upon any aspect of this experience in line with the pressing needs of his thinking. The "meanings" of words are, therefore, more fluid than we realize. For the foreign speaker of a language who learns this new language as an

246. For a mechanical procedure that shows word and morpheme boundaries see the recent article by Zellig S. Harris, "From Phoneme to Morpheme," Language, XXXI (1955), pp. 190-222.

${ }^{4}$ Charles C. Fries, with the cooperation of A. Aileen Traver, English Word Lists, A Study of Their Adaptability for Instruction, Washington, D.C., American Council on Education. Reprinted Ann Arbor, 1940, p. 87. 


\section{PATTERNS OF DIFFICULTY IN VOCABULARY}

adult, the words as stimuli probably never function with anything like the same fullness and freedom as they do for a native. ${ }^{5}$

1.4 Three aspects of words concern us here: (1) their form, (2) their meaning, and (3) their distribution.

1.41 Form. In most languages the form of words consists of sound segments, stress, and, in tone languages such as Chinese and Thai, pitch. The form of the Spanish word jugo 'juice' is made up of four significant sound segments (phonemes) /xúgo/ and stress-primary stress on the first syllable. If we change one of the sound segments, $j$, to $\underline{\mathrm{y}}$, a new word results, yugo 'yoke.' If we change the position of the primary stress, a new word results, jugo 'he played.' The Thai word 2น $[$ ma:?] 'horse' is made up of certain sound segments and a high, level pitch. The same segments with a rising pitch would mean 'dog.'

The form of words varies according to the formality of the situation, speed of talk, position in the sentence, position as to stress, etc. For example, the English word and varies from three segmental phonemes /aend/ through intermediate degrees of reduction, /ond/, /an/, /an/, to one segmental phoneme, /n/. The word not occurs as /nat/ and /nt/; will as /wll/ and as $/ \mathrm{l} /$; is as $/ \mathrm{zz} /$ and $/ \mathrm{s} /$ or $/ \mathrm{z} /$. Naive speakers of a language find it difficult to believe that the words they use vary so much in form.

Another relevant feature of form is that of the parts of words. English observational is made up of a stem observ(compare observe), 6 a suffix $-(a)$ tion, and another suffix -al . Other languages, on the other hand permit more complex combinations than those of English. As something of a linguistic curiosity, but definitely a form of the language, Sapir mentions the example from Paiute, wii-to-kuchum-punku rliganiyugwi-va-ntü-m(ii), meaning 'they who are going to sit and cut up with a knife a black cow (or bull) ${ }^{7}$

${ }^{5}$ lbid, $"$ p. 88.

${ }^{6}$ It is doubtful that native speakers break this form further into $a b+$ serve.

${ }^{7}$ Edward Sapir, Language, p. 31. 
The frequency of the parts of words may counteract the lack of frequency of the total word. If we use the word observational, it will probably be understood by elementary students of English as a foreign language even though it appears among the 1,358 least frequent words in Thorndike's list. ${ }^{8}$ The parts observe $+(a)$ tion + al are much more frequent than the word itself. The word observe is listed by Thorndike among the 2,000 most frequent words in English. The suffix -tion is used in so many words in English that its total frequency must be very high. I found examples of -tion in every page of a random ten page sample of Bloomfield's Language and in a similar spot-check of ten random pages of the lighter style of The Art of Plain Talk by Rudolf Flesch. The suffix -al. is less frequent than -tion, but it is still frequent enough to occur on practically every page of text.

English has lexical forms made up of patterns of separate words, for example call $\| p$ 'to phone.' Many languages do not permit such units or do not permit the same types of formal patterns. Compare for example Spanish telefonear 'to telephone' or llamar por telefono 'call by telephone' but nothing like the construction call $" p$.

1.42 Meaning. It is quite an illusion to think as even literate people sometimes do that meanings are the same in all languages, that languages differ only in the forms used for those meanings. As a matter of fact the meanings into which we classify our experience are culturally determined or modified and they vary considerably from culture to culture. Some meanings found in one culture may not exist in another. The meaning, 'horse' did not exist in American Indian languages until the Spanish conquest and colonization brought horses to America. Similarly, the meanings 'corn' (in the sense of maize) and 'potatoes' did not exist in Europe until the same people took those products from America to Europe in their ships. But even when the reality is available to the culture, the meanings will differ, or not exist in some cases. The Eskimos have many meaning distinctions corre-

8Edward L. Thorndike and Irving Lorge, The Teachers' Word Book of 30,000 Words, (New York 1944).

9Rudolf Flesch, The Art of Plain Talk, (New York, 1946). 


\section{PATTERNS OF DIFFICULTY IN VOCABULARY}

lating with different types of snow and use separate words to express those distinctions, whereas other cultures that have considerable experience with snow simply do not have as many meaning distinctions. These meaning differences are seldom as forcefully noticeable as when one attempts to translate accurately a text from one language to another.

Meanings can be classified according to the forms they attach to. Meanings that attach to words as words are lexical meanings, for example the meaning, 'a building for human habitation,' that attaches to the form house is a lexical meaning in English. The meaning 'two or more; plural' that attaches to the bound form $-s[\mathrm{~s}]$ in books, cats, maps, can be called a morphological meaning, while the same meaning 'plural' that attaches to the word form plural is a lexical meaning. The meaning 'question' attached to the word arrangement in the sentence, is he a farmer, is a syntactic meaning, but the meaning 'question' attached to the word form question is a lexical one.

At the moment, we are primarily concerned with lexical meanings, but different languages classify their meanings differently, that is, what is habitually a lexical meaning in one language may be a morphological meaning in another. Speakers of one language who have not come in meaningful contact with other languages assume not only that the meanings are the same but that they will be classified the same way. Speakers of English find it difficult to imagine a language in which the singular-plural distinction in book:books is not made morphologically. "How else can you communicate that idea?" they are apt to ask. In Chinese, for example, that distinction is not made, that is, it is not made morphologically, by a bound form such as $-s$ in English. In Chinese, the meanings 'two' 'three' 'more than one' etc. are lexical meanings; those meanings attach to words. When the meaning is relevant to the message, the words are included, and when the meaning is not relevant, the words are left out. Greek had the meanings 'singular' 'dual' and 'plural' as morphological meanings. We can assume that Greek speakers wondered how languages that have only singular and plural could express the meaning 'dual; two.' That distinction is a lexical one in English. 


\section{LANGUAGE LEARNING}

The matter of the frequency of the various meanings of a word is relevant to us. If one uses the word get, which appears among the 500 most frequent ones in Thorndike's list, in the context, We did not want to ourerdo the thing and get six months, meaning 'suffer imprisonment by way of punishment,' we would find that some fairly advanced students of English as a foreign language would not 'know' the word. Yet we could not convincingly assume that they did not really know one of the 500 most frequent words in English. That particular meaning of get is so infrequent that it was not reported as having occurred at all in a sample of over half a million running words. ${ }^{10}$ The Oxford English Dictionary lists 234 meanings for the word get and obviously one can know a good many of those meanings and still miss the word in the particular context used as an example above.

The meanings discussed are usually part of the intended message in communication. These meanings are more or less consciously intended by the speaker and may be called primary meanings. In actual use, however, other meanings are conveyed by words, for example, if a word is restricted in use to a given social class, its use by a speaker may give the listener the meaning of social class identification. Similarly if a word is restricted to a geographical area, its use by a speaker will convey a locality meaning, also.

1.43 The distribution of words is important to us because at any given moment in the history of a language the speakers of that language carry with them the habits of the restrictions in distribution and because different languages have different restrictions. There are grammatical restrictions so that in English, water may be a noun as in a glass of water, a verb as in water the garden, a noun adjunct as in water meter, but not an adjective without some change in form, e.g. watery substance. In other languages the restrictions may be greater; for example in Spanish, agua 'water' as a word may only be a noun unless its form is changed.

The fact that words may show different geographic distribution, falling in or out of this or that dialect area of a

10 Estimated from data supplied in Irving Lorge. 


\section{PATTERNS OF DIFFICULTY IN VOCABULARY}

language is important. And, as already indicated, distribution in the various social class levels also has to be considered because of the secondary meanings such distribution conveys. Statements of raw frequency alone leave these matters unresolved. Thorndike's list gives ain't among the 2,000 most frequent words in English, but the list does not say if ain't is typical of Standard English or of the speech representing certain other dialects.

Words are not only restricted geographically and socially; they are often restricted as to styles of speaking and writing. For example, many words found in poetry will not be found in ordinary conversation or in ordinary prose; and vice versa, some words used in prose will not be found in poetry.

1.5 Classifications. It should be abundatly clear from the above brief discussion if not previously so that the words of a language are more than merely a list of lexical items. The words of a language are a highly complex system of classes of items-interlocking classes as to meaning, form, grammatical function, distribution, etc.

1.51 Fries $^{11}$ classifies English words into four groups that seem relevant to us. They are (1) function words, (2) substitute words, (3) grammatically distributed words, and (4) content words. The function words primarily perform grammatical functions, for example, do signalling questions. The substitute words, he, she, they, so, etc. replace a class of words and several sub-classes. Grammatically distributed words, some, any, etc. show unusual grammatical restrictions in distribution. The number of words in the first three groups is rather small, say 200 in round numbers in English. ${ }^{2}$ The fourth group, content words, constitutes the bulk of the vocabulary of the language. In English and in many other languages the content words are subdivided into items treated as things, as processes, as qualities, etc.

11 Charles C. Fries, Teaching and Learning English as a Foreign Language, (Ann Arbor, 1945), pp. 44-50.

12 Estimated from data supplied in Fries, The Structure of English, (New York, 1954), Ch. VI. 


\section{LANGUAGE LEARNING}

1.52 Two further distinctions in vocabulary are required to complete our model. We need to distinguish between a common core vocabulary known to all the members of a language community, and specialized vocabularies, known only to special groups. We are of course primarily interested in the common core vocabulary, because specialized vocabularies have to be learned by native as well as non-native speakers. We are interested primarily in the special problems of the latter.

1.53 The other distinction is that between vocabulary for production and vocabulary for recognition. As a rule our recognition vocabulary is much larger than our production vocabulary. Various estimates have been made of the minimum necessary vocabulary for a student to be able to communicate in ordinary situations. Basic English uses approxmately 1,000 words for that purpose $!^{13}$ Michael West considers a vocabulary of 2,000 words "good enough for anything, and more than enough for most things."14 Obviously these are minimum production vocabularies. For recognition, larger minimum vocabularies are necessary.

\section{The Native Language Factor.}

2.1 Ease and difficulty. Given the above model and making use of available vocabulary studies one might attempt to select a sample vocabulary for teaching or for testing. Such attempts have been made and have received wide circulation. C. K. Ogden's Basic English list and West's A General Serice List of English Words is are well known examples in an active field. Nevertheless, in spite of the care and experience that has gone into the preparation of such lists, they cannot give us a vocabulary sample graded as to difficulty because by their very nature they fail to take

${ }^{13}$ C. K. Ogden, The System of Basic English, (New York, 1934).

${ }^{14}$ Michael West, "Simplified and Abridged," English Language Teaching, V, No. 2, p. 48 .

${ }_{15}$ Michael West, A General Service List of English Words with Semantic Frequencies and a Supplementary Word-List for the Writing of Popular Science and Technolog\%. (New York, 1953). 


\section{PATTERNS OF DIFFICULTY IN VOCABULARY}

into account the most powerful factor in acquiring the vocabulary of a foreign language, namely, the vocabulary of the native language.

If in a test of English vocabulary for Spanish speakers one uses the words machete. suppuration, and calumniator which appear among the 1,358 least frequent words in Thorndike's 30,000 word list, one would find that practically all the students knew them. Could we then assume that those students possessed a vocabulary of over 28,642 words in English? Obviously not. Spanish has the words machete, supuracion and calumniador, similar in form and meaning to the English words, and Spanish-speaking students will know those words by the mere fact of knowing Spanish. We simply cannot ignore the native language of the student as a factor of primary importance in vocabulary, just as we cannot ignore it in pronunciation and grammatical structure.

Another example arguing for the importance of the native language has to do with grammatical distribution of two very simple words. The words fire and man will probably be more difficult for Spanish speakers in the contexts, Fire the furnace, and Man the guns, than in Open fire 'start shooting' and $A$ man broke his leg. The difference is more subtle than in the previous example, but it is there nevertheless. Spanish has a noun, fuego, 'fire' used in Abran fuego, 'Open fire' but not used as a verb as in Fire the furnace. Similarly, a Spanish noun, hombre, 'man,' is used in Unhombre se rompió una pierna, 'A man broke his leg,' but is not used as a verb as in Man the guns. There are other elements involved in these examples to be sure, but grammatical distribution is definitely a factor.

2.2 Difficulty patterns. Similarity and difference to the native language in form, meaning and distribution will result in ease or difficulty in acquiring the vocabulary of a foreign language. Comparing the foreign language vocabulary with that of the native language we will find words that are (1) similar in form and in meaning, (2) similar in form but different in meaning, (3) similar in meaning but different in form, (4) different in form and in meaning, (5) different in their type of construction, (6) similar in primary meaning but different in 
connotation, and (7) similar in meaning but with restrictions in geographical distribution.

Since some of these groups overlap, with the result that some words will fall into more than one group at the same time, the difficulty will vary somewhat. Nevertheless, we can predict general level of difficulty on the basis of these groupings, and will classify each group into one of three levels of difficulty: (1) easy, (2) normal, and (3) difficult.

The term similar is restricted here to items that would function as "same" in the other language in ordinary use. We know that complete sameness is not to be expected in language behavior. The actual behavioral boundaries of similarity depend on the items that persons of one language "identify" or "translate" as same from and into the other language. References to form are to the sounds of the words, not to the spelling, even though spelling is used to represent the words in this paper.

Pattern 1, Cognates: 16 words that are similar in form and in meaning. English and Spanish have thousands of words that are reasonably similar in form and in meaning, for example hotel, hospital, calendar. ${ }^{17}$ Some of these were kept in Spanish as it evolved from Latin and were borrowed into English from Latin or French. Some go back to earlier forms presumably found in Indo-European, the common ancestor of English and Spanish in what is known as the IndoEuropean family of languages. Whatever the cause of the similarity, these words usually constitute the lowest difficulty

\footnotetext{
${ }^{16}$ Cognates here mean words that are similar in form and meaning regardless of origin. The usual meaning of cognate is "related in origin." For us even if two words are not related in origin they will be called cognates if they are similar in form and meaning. Similarly, if two words have the same origin but are now so different that speakers do not identify them as similar, they will not be considered cognates for our purpose.

${ }^{17}$ For a list of Spanish-English cognates see Marshall E. Nunn, and Herbert A. Van Scroy, Glossary of Related Spanish-English Words, University of Alabama Studies, Number 5.
} 


\section{PATTERNS OF DIFFICULTY IN VOCABULARY}

group-they are easy. In fact, if they are similar enough, even students who have never studied English at all will recognize them. These words are of value at the very elementary level.

Even though there are thousands of words that are similar in English and Spanish these similarities can be classified into a relatively small number of sub-patterns, for example, English -tion is similar to Spanish -cion, and hundreds of words can be classified as similar under that sub-pattern. ${ }^{18}$ When using such words in teaching and testing beginning students we will do well to sample them as sub-patterns rather than as independent items.

Vigorous discussion often results when cognate words are mentioned in connection with teaching. We do not need to get involved in such discussions since cognates are presented here for recognition rather than for production. There can be little quarrel with having the student recognize them when they are used by others.

It is sometimes falsely assumed that cognates are to be found only between two related languages such as English and Spanish, not between unrelated languages such as English and Japanese, Chinese and English. In actual fact, numerous cognates can be found between English and Japanese and between English and Chinese, and many other languages which are quite unrelated to each other. There are many words which have circled the globe, and many more that have extended far beyond the boundaries of any one language or any one culture.

Pattern 2, Deceptive Cognates: 19 Words that are similar in form but represent meanings that are different. Words

\footnotetext{
${ }^{18}$ For a brief account of nine patterns of Spanish-English cognates see Lessons in Vocabulary', from An Intensive Course in English by the Research Staff of the English Language Institute, Charles C. Fries, Director, (Ann Arbor, 1954). Compare also E. M. Anthony "The Teachings of Cognates", Language Learning, IV (1952-53), pp. 79-82.

${ }^{19}$ Deceptive cognates" as used here refers only to similarity in form and difference in meaning; it does not refer to the origin of the words.
} 
that are similar in form in two languages may be only partly similar in meaning, they may be altogether different in meaning but still represent meanings that exist in the native language, or they may be different in meaning and represent meanings that are not grasped as such in the native language. Japanese borrowed the word milk from English but restricted its meaning to 'canned milk.' The form of the word in Japanese is similar to English but the meaning is only partly similar since it does not include fresh milk, for example. Spanish has a word, asistir, which is similar in form to English assist, but the meaning is practically always different. Spanish asistir is similar in meaning to English attend, while English assist carries with it the feature of helping, of supporting. As a result of this difference in meaning, Spanish speakers learning English say they assisted a class when meaning they attended 'were present.' English in the talle and on the table are similar in meaning to Spanish en la mesa in ordinary conversation. Only under very special circumstances will a Spanish speaker make a meaning distinction between in. and on the table, and then it will not be only an in:on contrast but a table vs. drawer contrast as well. Spanish speakers will say en el cajón 'in the drawer' and sobre la mesa 'on the table.' The problem here is not simply attaching a familiar meaning to a new form but also grasping a new meaning distinction, a different way of classifying reality.

These words that are similar in form but different in meaning constitute a special group very high on a scale of difficulty. We will label them difficult. They are not adequately sampled on frequency criteria alone because their similarity in form to words in the native language raises their frequency in student usage above normal for the language. In other words, they are more important than their frequency rating might indicate. They are sure-fire traps.

In usual linguistic terminology deceptive cognates would refer to words in two languages that because of their form would seem to be related by origin but are not so related. For us such a case would be classed as a cognate provided the sueanings are also similar. 


\section{PATTERNS OF DIFFICULTY IN VOCABULARY}

Pattern 3, Different Forms: Words that are similar in some of their frequent meanings but different in form. Difficulty level: normal. Example. English tree in the context, The leaves of that tree are falling, is similar in its primary meaning to Spanish arbol in a comparable context. The learning burden in this case is chiefly that of learning a new form, tree, for a meaning of arbol already habitually grasped by Spanish speaking students. This kind of vocabulary learning is na'ively taken by many to represent all vocabulary learning. Such an oversimplification fails to account for the various vocabulary groups which appear when we have looked closer and have considered the native language.

It is also important to note that although certain meanings of a word in one language are sometimes translatable into a word in another language there are very few if any words in two languages that are the same in all their meanings. It is difficult for example to realize that the words tree and arbol of our example are similar in only about four out of their twenty or more meanings and uses. Only the poorest twolanguage dictionaries will show numbers of words in a one-toone meaning correspondence in the two languages. Only words such as penicillin, which are borrowed into many languages simultaneously, can be considered equivalent in all their meanings, and even then if such words gain any currency at all they soon develop new meanings that are not parallel in different languages.

It is in these content words that are different in form but similar in some meanings, however, that decisions can and should be made as to vocabulary size on the basis of frequency lists for recognition and adequacy for expression on a production level.

Pattern 4, "Strange" Meanings: Words that are different in form and represent meanings that are "strange" to speakers of a particular native language, that is, meanings that represent a different grasp of reality. Difficult. In American English, first floor is different in form from Spanish primer piso and different in its grasp of what constitutes 'first.' Spanish primer 'first' in this case does not mean number one at ground level but number one above ground level, and so 
primer piso refers to what in Am. English is called second floor and not first floor, which would be the literal translation.

These cases constitute special problems in the vocabulary of a foreign language. Obviously it is not enough merely to teach a new form; the strange meaning must be made familiar. Some of the instances covered by this pattern-the instance in which the form in the two languages is similar-fall also under pattern 2, deceptive cognates. Pattern 4, however, includes all those in which there is no particular similarity in the form of the words in the two languages.

There is every reason to believe that the same kind of distortion that we can observe in the sounds of the speech of a non-native speaker also occur in the meanings he is trying to convey. In both cases he is substituting sounds and meanings of his native language and culture. In the case of sounds the untrained person hears a vague "foreign" accent and the trained person hears specific distortions. In the case of meanings the distortions go largely undetected by the observer or listener because the native meanings stimulated in him by the speech forms may not be accompanied by outwardly observable behavior. It is only when a word form is used in an "unusual" way that our attention is drawn to possible meaning differences. Similarly, when the non-native speaker of a language listens to the language as sppken by natives, the meanings that he grasps are not those that the native speakers attempt to convey, but those of the system of the language of the listener.

Pattern 5, New Form Types: Words that are different in their morphological construction. Difficult. When the speakers of various Romance languages and of Japanese, Chinese and other languages learn English they have great trouble learning such lexical items as call up 'to telephone,' call on 'to visit,' and run out of to exhaust the supply of.' If in the native language of the student there are no lexical items made up of two otherwise separate words in patterns like the one illustrated, he will not easily grasp these "two-word verbs" in the foreign language. The difficulty is increased when the elements can be separated by other words as in the example, Did you call the boy up? These two-word verbs constitute a difficulty group all its own for speakers of various languages. 
"Idioms"-expressions peculiar to a language-are identifiable as we compare two languages rather than within the language itself. An expression which may seem peculiar to native speakers may be quite natural to speakers of another language and would therefore not be an "idiom" to them. On the other hand, an expression which seems quite natural to native speakers may be strange to foreign speakers of a particular language background. If we should find on comparing the expression with a variety of languages that it is strange to all or nearly all of them, we would be justified in calling it an idiom in general, but even then the statement would be meaningless in those cases in which the other language had a parallel expression. As a matter of fact, the idiom counts made in the wake of the Modern Foreign Language Study were two-language studies. The Spanish Idiom List by Keniston ${ }^{20}$ lists expressions in Spanish that are strange to English speakers. In all of the counts the compilers looked at expressions in the foreign language with English as their frame of reference.

Pattern 6, Different Connotation: Words that have widely different connotations in two languages. Difficult. A special difficulty group is represented by words that are harmless in connotation in the native language but offensive or taboo in the foreign language, or vice versa. When they are harmless in the native language the student will use them in the foreign language without realizing their effect. When they are harmless in the foreign language the student will avoid using them for fear of setting off the same reactions they produce in his native language. In either case they are important on the level of social acceptability of words. A few examples will show how important these connotation differences can be.

In Spanish the expression Dios mío meaning literally ' $\mathrm{My}$ God' is often used as an appeal to the Almighty in matter-offact conversation. Even those Spanish speakers who have progressed considerably in their control of English will sometimes use the expression with the same feeling and intent in

\footnotetext{
${ }^{20}$ Hayward Keniston, Spanish Idiom List Selected on the Basis of Range and Frequency of Occurrence. Publications of the American and Canadian Committees on Modern Languages. XI (New York, 1929).
} 


\section{LANGUAGE LEARNING}

English, but the effect on English listeners is of course different. The name Jesús is often used as a given name in Spanish. Parents who thus name their children may actually feel they are honoring Christ, or at least do not feel any lack of respect. In English, however, people find it difficult to call a person by that name. It seems to smack of irreverence to English speakers to use the name for a human being, a radically different connotation from that in Spanish. In whistling at sports events or political rallies the difference is in the opposite direction: Spanish speakers may be shocked to hear a speaker whistled at and applauded at the same time. They believe the whistles indicate disapproval and they wonder why disapproval is expressed so openly as it appears to them. In Spanish the applause indicates approval, and whistling, a vulgar form of disapproval. Some youthful students of foreign languages delight in learning certain unprintable expressions not approved in polite company. When they ask for translations they get colorless renderings which when uttered leave us wondering why they are uttered at all.

These differences in connotation sometimes develop between dialects of the same language. In Cuba the familiar form of the second person pronoun, tiu, is more widely used than in Mexico for example. A Cuban young man was rebuked by two Mexican young ladies because he used the familiar $t \bar{u}$, which sounded a bit too bold to them. No amount of explaining was enough to completely convince the girls that the young man actually meant no disrespect. The word grueso 'fat' is used as a compliment at least in some dialects of present day Spanish. On a visit to Spain I was greeted repeatedly with "flattering" expressions of how "fat" I was. Being aware of the favorable connotation I appreciated the remark, but many an American young girl may not have felt flattered.

These have been obvious, even coarse examples of wide differences in connotation. More subtle differences exist and remain in the speech of speakers of foreign languages through the advanced stages of control of the language. We cannot do much to teach or to test these subtle differences specifically and completely, but it is possible to sample the more frequent and obvious cases of wide discrepancy in connotation. 


\section{PATTERNS OF DIFFICULTY IN VOCABULARY}

Pattern 7, Geographically Restricted: Words that are restricted as to the geographic areas in which they are used in the foreign language. Difficult, because the restrictions must be learned also. Restrictions in geographic distribution of words are important to the selection of words for teaching and for testing. Unless we are interested in teaching or testing a particular geographic dialect of a language we will choose forms that are part of the standard language if there is one, and words that are common to the major dialects if there is not a standard language. If we are interested in English without regard to whether it is Standard British or Standard American English we would avoid such words as petrol and gasoline in testing because they are typical of British and American usage respectively. If on the other hand we are interested in Standard American English as distinct from British English, we would use gasoline. Within American English, if we are not interested in any one dialect, we would use dragon $f l y$ for the insect known by that name, because that term is more general than Northern darning needle and Midland snake feeder for the same insect. ${ }^{21}$

Although part of what has been said about pattern 7 seems not to apply directly to the definition of a pattern of difficulty, it is an important consideration. The matter of geographic distribution fits more neatly into a difficulty pattern when we consider that a student who has learned a geographically restricted form must learn another for the same meaning if he is to communicate with speakers from geographic areas where the form he learned has no currency. Hence, the label "difficult" we have given the pattern.

$$
\text { *************** }
$$

There has been on the whole much superficial oversimplified thinking about the vocabulary of languages, and a great deal of vocabulary research such as word frequency lists and simplified vocabularies suffers from that oversimplification. In dealing with vocabularly we should take into account three important aspects of words--their form, their meaning, their distribution--, and we should consider the various kinds or

${ }^{21}$ Hans Kurath, A Word Geography of the Eastern United States. (Ann Arbor, 1949), p. 14. 


\section{LANGUAGE LEARNING}

classes of words in the operation of the language. If these things are important in understanding the vocabulary system of a language, they become even more important when one learns the vocabulary of a foreign language since the forms, meanings, distribution, and classifications of words are different in different languages. Out of these differences arise vocabulary problems and difficulty levels that constitute teaching and learning problems and are telltale matters for vocabulary tests. The patterns of difficulty described above are an attempt to clarify and classify the problems involved.

\section{References}

Bloomfield, Leonard. Language. New York: Henry Holt and Company, 1933.

Bongers, Herman. The History and Principles of Vocabulary Control. Woerden, Holland: Wocopi. Three volumes in two, 1947.

Flesch, Rudolf. The Art of Plain Talk. New York and London: Harper \& Brothers Publishers, 1946.

Fries, Charles C., with the cooperation of A. Aileen Traver. English Word Lists. A Study of Their Adaptability for Instruction.Washington, D.C.: American Council on Education, 1940. Reprinted 1950 by The George Wahr Publishing Co., Ann Arbor.

Fries, Charles C.

Teaching and Learning English as a Foreign Language. Ann Arbor: University of Michigan Press, 1945.

The Structure of English. New York: Harcourt, Brace and Co., Chapt. VI, 1954.

Keniston, Hayward.Spanish Idiom List, Selected on the Basis of Range and Frequency of Occurrence. New York: Publications of the American and Canadian Commmittees on Modern Languages. Vol. XI, 1929.

Kurath, Hans. A Word Geography of the Eastern United States, Ann Arbor: University of Michigan Press, 1949.

Lorge, Irving. The Semantic Count of 570 Commonest English Words. New York: Bureau of publications, Teachers College, Columbia University, 1949. 


\section{PATTERNS OF DIFFICULTY IN VOCABULARY}

Nunn, Marshall E., and Van Scroy, Herbert A. Glossary of Related Spanish-English Words. University, Alabama: University of Alabama Studies, Number 5, 1949.

Ogden, C. K. The System of Basic English. New York: Harcourt, Brace and Company, 1934.

The Oxford English Dictionary. Vols. I-XII and Supplement (Corrected Reissue). Oxford University Press, 1933.

Rodriguez Bou, I. Recuento de vocabulario español. Río Piedras, Puerto Rico: Universidad de Puerto Rico. Two volumes in Three, 1952.

Sapir, Edward. Language. New York: Harcourt, Brace and Co., 1921.

Thorndike, Edward L., and Lorge, Irving. The Teacher's Word Book of 30,000 Words. New York: Bureau of Publications, Teachers College, Columbia University, 1944.

West, Michael. "Simplified and Abridged," English Language Teaching, 5, no. 2 (Nov.): 48-52, 1950.

A General Service List of English Words, with Semantic Frequencies and a Supplementary Word-List for the Writing of Popular Science and Technology. London; New York; Toronto: Longmans, Greene and Co., 1953. 